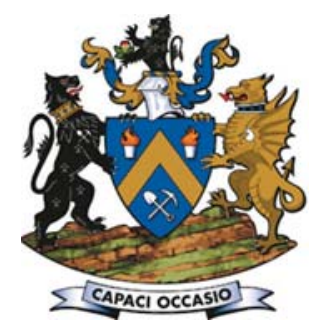

\title{
Uranium recovery from high-chloride sulphate leach solutions: A cost trade- off study of using treated water vs. saline water as make-up water
}

\author{
by E.L. Forner*, S.J. Archer*, V.E. Coetzee* ${ }^{*}$ K. Soldenhoff ${ }^{\dagger}$, \\ and J. Quinn ${ }^{\dagger}$
}

\section{Synopsis}

A well-established technology for uranium recovery comprises sulphuric acid leaching, followed by solvent extraction (SX) with tertiary amines such as Alamine 336. The inherent challenge with uranium processing in arid mining regions, such as Namibia and Australia, is that good quality water sources are in short supply. Supplying water through a desalination facility is a costly solution, and the use of high-salinity water, for example, seawater or saline bore water, could provide an alternative option. However, the presence of chlorides above $3 \mathrm{~g} / \mathrm{L}$ in the pregnant leach solution hinders uranium loading on the conventional tertiary amine solvent extraction organic. In this paper, the opportunity to utilize highsalinity water $\left(20 \mathrm{~g} / \mathrm{L} \mathrm{Cl}^{-}\right)$as make-up water in the plant is evaluated using two uranium solvent-extraction (SX) recovery options: Option 1 employs a large seawater reverse-osmosis treatment plant for the supply of fresh water throughout the process, together with Alamine 336 organic for SX; option 2 uses saline water for the front-end water requirements, with the chloride-tolerant Cyanex 272 organic for purification and a smaller reverse osmosis plant for fresh water supply downstream of SX. The main focus is the selection of materials of construction as well as the capital and operating expenditure differentials for water treatment and front-end unit operations. A high-level techno-financial trade-off study using cost differentials revealed that a flow sheet incorporating a highsalinity water source is an economical option when mild steel rubber-lined platework and super-duplex SAF2507 steel mechanicals are used.

Keywords

uranium recovery, solvent extraction, chloride tolerance, high-salinity.

\section{Introduction and literature review}

There is an inherent challenge associated with mining in arid regions, such as Namibia and Australia, in identifying a clean source of water for use in the processing plant. Alternative sources such as borehole water or seawater tend to have a high salt content. The presence of chloride, in particular, is problematic because of its deleterious impact on uranium solvent extraction with conventional long-chain tertiary amine reagents such as Alamine 336 (Morais and Ladeira, 2008; Soldenhoff et al., 2000).

Research has been ongoing to identify solvent extraction (SX) processes that are chloride-tolerant. Different reagents have been proposed, including:

\section{$>$ Mixed reagents, di- $(2-$} ethylhexyl)phosphoric acid and tertiary amine (DEHPA/Alamine 336) (Quinn,
Wilkins, and Soldenhoff,; Soldenhoff et al., 2000, 2005)

> Solvating reagent, based on phosphine oxide blends (Dudley and Sumner, 2014)

> Single reagent, bis $(2,4,4$ trimethylpentyl)phosphoric acid (Cyanex 272) (Soldenhoff and Quinn, 2015).

The DEHPA/Alamine 336 process has been applied at industrial scale (Ballestrin et al., 2014). Sodium carbonate is used for stripping. Challenges associated with this process include crud formation due to iron carry-over to the strip circuit, solvent loss, and third-phase formation (Ballestrin et al., 2014; Quinn, Wilkins, and Soldenhoff, 2013). Sulphuric acid stripping has been tested with this reagent mix, but the concentration of acid required is significantly greater than that used in conventional strong-acid strip circuits using tertiary amines (Soldenhoff et al., 2005).

The application of phosphine oxide-type reagents, such as tri-octyl phosphine oxide (TOPO), has also been reported. These reagents are not amenable to sulphuric acid stripping, and ammonium sulphate has been suggested (Dudley and Sumner, 2014).

A study on the application of Cyanex 272 in this context has shown that high uranium loadings can be achieved at chloride concentrations commensurate with those found in seawater. Furthermore, the solvent is selective for uranium over ferric and can be stripped with $4 \mathrm{M} \mathrm{H}_{2} \mathrm{SO}_{4}$ (Quinn and Soldenhoff, 2015). A comparative study examining these options with respect to uranium loading, selectivity over ferric ion, response to strong acid stripping, and

* DRA Projects, South Africa.

+ ANSTO Minerals, South Africa.

(C) The Southern African Institute of Mining and Metallurgy, 2018. ISSN 2225-6253. This paper was first presented at the Uranium 2017 International Conference, 12-13 September 2017, Swakopmund Hotel, Swakopmund, Namibia.. 


\section{Uranium recovery from high chloride sulphate leach solutions}

requirement for phase modifier showed that Cyanex 272 performed best against these process-relevant criteria (Soldenhoff and Quinn, 2015).

The presence of chloride has wide-ranging implications for the overall hydrometallurgical flow sheet, apart from its impact on the SX process. The broader implications of operating in a high chloride environment have not previously been considered in detail. In this paper, we examine the relative merits of using a conventional SX process for uranium based on tertiary amines, coupled with a water treatment plant to remove chloride, as opposed to using a chloride-tolerant SX process based on Cyanex 272 coupled with high-salinity process water. The relative merits of these two approaches are compared with reference to the implications for the capital and operating expenditure (CAPEX and OPEX).

\section{Comparison of flow sheets}

Two uranium SX recovery circuits were modelled and compared. The differences in the overall flow sheets are presented in Figure 1 and Figure 2.

1. Option 1 (conventional uranium SX with treated water) - employs a large seawater reverse osmosis (SWRO) treatment plant for the supply of fresh water throughout the entire process, together with the use of standard Alamine 336 organic in the SX unit operation.

2. Option 2 (chloride-tolerant uranium SX with saline water) - uses saline/seawater as the water source for the front-end unit operations, together with Cyanex 272 organic for extraction of uranium. Key unit operations downstream of SX still necessitate a SWRO for the supply of treated water, although on a significantly smaller scale. The RO water treatment plant could have been even smaller, essentially just for product washing as SX stripping can be done with seawater and $\mathrm{H}_{2} \mathrm{SO}_{4}$. However, the nanofiltration circuit would need to be tested for acid recovery in high-chloride solutions. In this option, a chloride concentration in the process water in the order of $20 \mathrm{~g} / \mathrm{L} \mathrm{Cl}^{-}$was modelled, similar to that in seawater. It was assumed that there is no chloride contribution from the ore. Peroxide precipitation was modelled for both flow sheets to facilitate comparison of the two flowsheets on the same basis.

One of the main factors affecting the selection of the unit operation for uranium purification is the uranium tenor of the pregnant leach solution (PLS). An ore head grade of $650 \mathrm{ppm}$ $\mathrm{U}_{3} \mathrm{O}_{8}$, typical of areas such as Namibia, was used for this trade-off. After leaching, with a uranium recovery of about $89 \%$, the PLS typically contains $0.52 \mathrm{~g} / \mathrm{L} \mathrm{U}_{3} \mathrm{O}_{8}$. According to Brown and Haydon (1979), SX is economically favoured over ion exchange (IX) at PLS tenors greater than $0.9 \mathrm{~g} / \mathrm{L} \mathrm{U}_{3} \mathrm{O}_{8}$, whereas IX is more economical below $0.35 \mathrm{~g} / \mathrm{L} \mathrm{U}_{3} \mathrm{O}_{8}$. Additionally, at higher uranium concentrations, SX is beneficial after countercurrent decantation (CCD) (van Tonder and Kotze, 2007). Accordingly, the overflow from the CCD in the two flow sheets is recycled to leach to build the PLS uranium tenor in order to warrant the use of SX instead of IX, and the overflow from the post-leach thickener proceeds to $\mathrm{SX}$ at a higher tenor of $0.83 \mathrm{~g} / \mathrm{L} \mathrm{U}_{3} \mathrm{O}_{8}$.

In this paper, we traded off the materials of construction (MoC) for two treated water options (1a and $1 \mathrm{~b}$ ) and two seawater options (2a and $2 \mathrm{~b}$ ), shown in Figure 3. Option 1a considered mild streel rubber-lined (MSRL) platework and represented the basis of comparison. Option 2 a considered the equivalent materials of construction for circuits containing high chlorides $\left(20 \mathrm{~g} / \mathrm{L} \mathrm{Cl}^{-}\right)$. The other two options $(1 \mathrm{~b}$ and $2 \mathrm{~b}$ ) offered more corrosion-resistant $\mathrm{MoC}$ for mechanical equipment and platework.

\section{CAPEX differentials}

Materials selection and corrosion resistance

Materials selection for high-saline applications with soluble

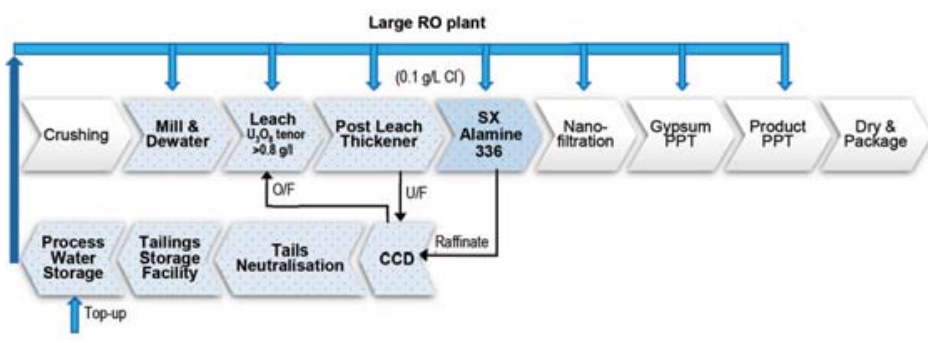

Figure 1-Option 1 (treated water) flow sheet highlighting costed differential unit operations

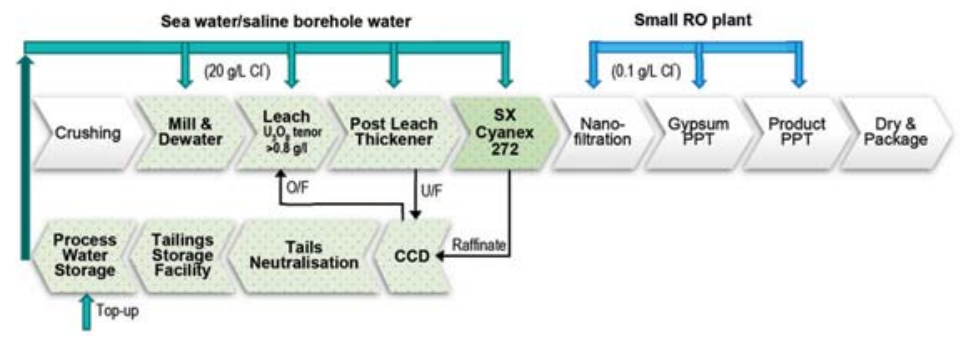

Figure 2-Option 2 (seawater) flow sheet highlighting costed differential unit operations 


\section{Uranium recovery from high chloride sulphate leach solutions}

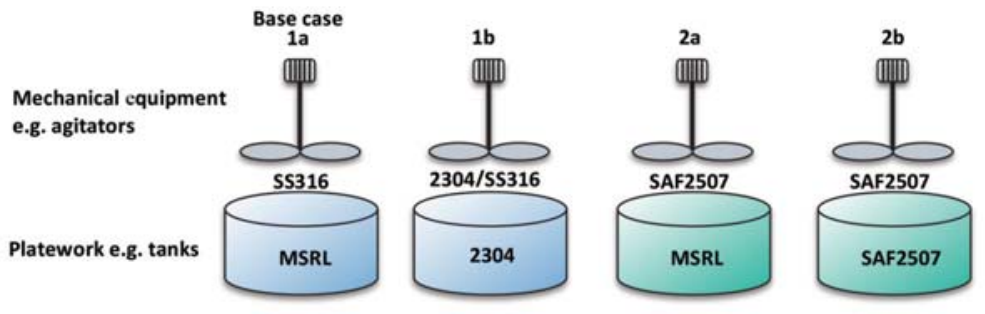

Figure 3-Four options evaluated in terms of capital expenditure (CAPEX) and operating expenditure (OPEX)

salts/sulphates depends on many factors, including salt concentration, acid concentration/pH, materials composition, compatibility, and strength, processing characteristics (abrasion), as well as cost and availability. Newer high-alloy stainless and duplex steels, which were unavailable a few decades ago, are now commonplace as MoC.

Soluble salts, particularly chlorides and sulphates, initiate and accelerate corrosion of steel, becoming deeply embedded within the iron corrosion products. Furthermore, when selecting linings for carbon- or mild steel tanks, cognisance needs to be taken of operating conditions. In this section, the factors influencing material selection are reviewed. The benefits and limitations associated with common steels and tank linings implemented in modern-day hydrometallurgical applications are also discussed.

- Pitting resistance equivalent number (PREN) - PREN is a theoretical way of comparing and ranking the pitting corrosion resistance of various types of stainless steels, based on their contents of chrome, nickel, and molybdenum. Steels with PREN less than 32 are generally not considered corrosion-resistant in seawater. According to the empirical relationship (Equation [1]), the pitting resistance of stainless steel alloys increases as the contents of these three alloying elements are raised. The typical compositions of some stainless steels incorporated in this study are given in Table I, which also provides data on their mechanical properties (Goldswain and Rogers, 2017a), PREN, and critical pitting temperature (CPT).

PREN $=\% \mathrm{Cr}+3.3 \times \% \mathrm{Mo}+16 \times \% \mathrm{Ni}$

- Critical pitting temperature (CPT)-There is no single measure of corrosion resistance and PREN alone cannot be used to predict whether a particular grade will be suitable for a given application where pitting corrosion may be a hazard. Hence, an additional means of ranking steels is used, namely the CPT, which uses an electrochemical method, ASTM G150, in $1 \mathrm{M} \mathrm{NaCl}$. In this test, the temperature is determined when pitting starts to develop (Outokumpu, 2013).

> Steel mechanical strength-Duplex stainless steels have roughly twice the yield strength of their counterpart austenitic grades. This allows equipment designers to use thinner gauge material for vessel construction, resulting in large savings in the manufacturing phase. The tank walls can be significantly thinner, yet safe in use (Goldswain and Rogers, 2017b).

> Rubber linings and epoxy coatings are subject to certain limitations in their application:

- Contaminants, such as soluble salts on a steel surface, can prevent bonding during application and establish osmotic driving forces promoting water permeation and blistering of rubber lining

- Organic coatings like natural rubber dissolve and swell in the presence of the organic solvents used in SX circuits; therefore, no rubber-lined platework is used in SX

- Organic coatings and solvents are also susceptible to thermal degradation. The uranium circuit is therefore designed for temperatures less than $40^{\circ} \mathrm{C}$.

\section{Materials selection and costs}

Each data point shown in Figure 4 represents the cost ranking of a fabricated tank, at a specific size/volume, in a selected material, relative to a $9 \mathrm{~m}^{3}$ mild steel tank.

Fabrication implies the cost of material and the cost of labour has been accounted for. Typically, the fabricated cost is twice the material cost (Goldswain and Rogers, 2017b).

Table I

Comparative material compositions (mass \%), PREN, CPT corrosion resistance $\left({ }^{\circ} \mathrm{C}\right)$, and mechanical strength (0.2\% proof $\mathrm{MPa}$ ) for duplex and austenitic steels (Outokumpu, 2013)

\begin{tabular}{|c|c|c|c|c|c|c|c|c|c|c|}
\hline MoC & Type & C (\%) & N (\%) & $\mathrm{Cr}(\%)$ & $\mathrm{Ni}(\%)$ & Mo (\%) & Other & PREN - & $\mathrm{CPT}\left({ }^{\circ} \mathrm{C}\right)$ & Yield strength $\left(\mathrm{P}_{0.2} \mathrm{MPa}\right)$ \\
\hline MS epoxy & Ferritic & 0.25 & & & & & $99 \mathrm{Fe}$ & $\mathrm{N} / \mathrm{A}$ & & 250 \\
\hline MSRL & Ferritic & 0.25 & & & & & $99 \mathrm{Fe}$ & N/A & & 250 \\
\hline SS316L & Austenitic & 0.02 & & 17.2 & 10.1 & 2.1 & & $24-25.2$ & 21 & 220 \\
\hline LDX2101 & Lean duplex & 0.03 & 0.22 & 21.5 & 1.5 & 0.3 & $5 \mathrm{MnCu}$ & 26 & 20 & 450 \\
\hline 2304 & Lean duplex & 0.02 & 0.1 & 23 & 4.8 & 0.3 & $\mathrm{Cu}$ & 26 & 28 & 400 \\
\hline SS904L & Austenitic & 0.01 & & 20 & 25 & 4.3 & $1.5 \mathrm{Cu}$ & 34 & 65 & 220 \\
\hline 2205 & Duplex & 0.02 & 0.17 & 22 & 5.7 & 3.1 & & 35 & 55 & 460 \\
\hline SAF2507 & Super-duplex & 0.02 & 0.27 & 25 & 7.0 & 4.0 & & 43 & 88 & 530 \\
\hline
\end{tabular}




\section{Uranium recovery from high chloride sulphate leach solutions}

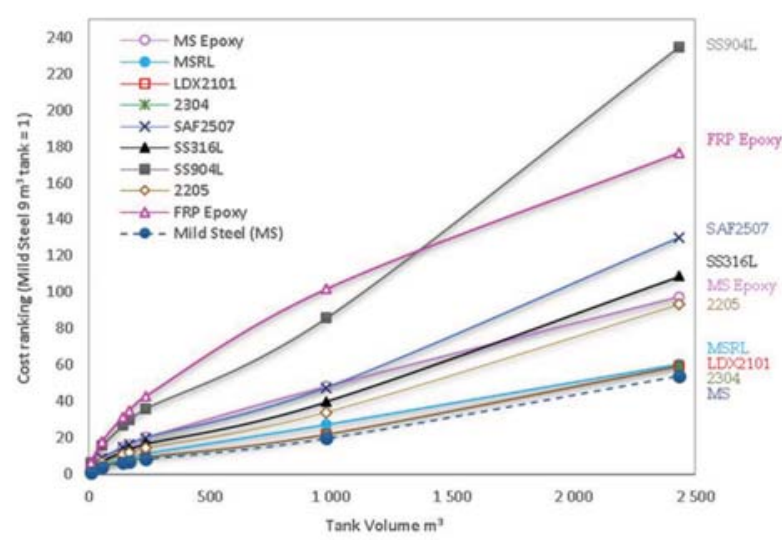

Figure 4-Rankings of fabricated tank costs for various platework materials of construction and tank sizes compared to a $9 \mathrm{~m}^{3}$ mild steel tank

Material quantities were estimated using DRA's bill of quantities. Tank platework material quantities were then factored based on the storage tank shell thickness tool provided by Outokumpu (2015). The tool is based on API650 and EN14015 standards, which allowed us to estimate the material consumption for the cylindrical shell of a tank and to compare how steel grade affects material consumption and cost. We also considered the cost differentials of shop- and site-fabricated tanks.

\section{Materials of construction differentials}

In this paper, we traded off MoC for two treated water options ( $1 \mathrm{a}$ and $1 \mathrm{~b}$ ) and two seawater options ( $2 \mathrm{a}$ and $2 \mathrm{~b})$, shown in Table II. Option 1a considered mild streel rubber-lined (MSRL) platework and represented the basis of comparison. Option $2 \mathrm{a}$ considered the equivalent materials of construction for circuits containing high chlorides $\left(20 \mathrm{~g} / \mathrm{L} \mathrm{Cl}^{-}\right)$. The other two options ( $1 \mathrm{~b}$ and $2 \mathrm{~b}$ ) offered more corrosion-resistant $\mathrm{MoC}$ for mechanical equipment and platework. Mechanical equipment included agitators and thickener rake mechanisms. Platework included tank and thickener shells. These parameters were applied only to the wetted unit operations of the front-end circuit shown in Figure 1.

For all options, the mill and thickener platework was mild steel with rubber liners/lining. DRA has implemented mills/scrubbers with rubber liners and anodic protection in high-chloride seawater applications. Two such projects include De Beers' diamond-mining vessels operating off the Namibian coast, involving preferential Kawasaki ball mills as well as the mill installed on the Ya Toivo.

- Options 1a and $2 a$-Rubber linings and epoxy vinyl ester coatings exhibit excellent compatibility with dilute sulphuric acid (up to $5 \mathrm{~g} / \mathrm{L} \mathrm{H}_{2} \mathrm{SO}_{4}$ ) that will be present in the leach and CCD areas. Rubber lining and epoxy coating are also highly resistance to chlorides in option $2 a$, if correctly applied to the tank surfaces. Mild steel/epoxy coating is more costly than mild steel/rubber lining. Consequently, we used rubber as the lining for the mild steel options (1a and $2 \mathrm{a}$ ).

> Option 1b-This option represented 'standard' materials of construction for a conventional uranium processing circuit where chlorides are not of concern Historically, SS316 has been a 'safe' material to specify for use on hydrometallurgical plants, although there has been a move to duplex in recent years. The PREN number for SS316 is 24, compared with 26 for LDX2101® and 2304. In terms of corrosion resistance, the 'good/better/best' basis would be SS316/LDX2101®/2304. Lean duplex steel 2304 has a CPT of about $28^{\circ} \mathrm{C}$, while LDX2101® has a CPT of around $20^{\circ} \mathrm{C}$.

> Option 2b-In dilute sulphuric acid contaminated with chloride ions:

- Super-duplex steel SAF2507 has better corrosion resistance than SS904L, which is a highly alloyed austenitic steel grade specially designed to resist sulphuric acid (shown in Table I by a higher PREN and CPT, $88^{\circ} \mathrm{C}$ for SAF2507 versus $65^{\circ} \mathrm{C}$ for SS904L)

- The material cost of SS904L is approximately double that of SAF2507

- Thinner gauge material (less material) is used with SAF2507 than SS904L due to the higher mechanical strength of SAF2507 (shown in Table I by the $0.2 \%$ proof yield strength).

For these reasons, SAF2507 was selected as the 'highspecification' material (option 2 b) for seawater.

\section{Solvent extraction circuit differentials}

The main differentials affecting CAPEX were due to SX circuit size and are summarized in Table III. The equipment size

Table II

Materials of construction differentials for two treated-water and two seawater flowsheet options

\begin{tabular}{|c|c|c|c|c|}
\hline Unit operation & $\begin{array}{c}\text { Treated water } \\
\text { large RO } \\
\text { Alamine SX } \\
\text { Base case 1a }\end{array}$ & $\begin{array}{c}\text { Treated water } \\
\text { large RO } \\
\text { Alamine SX } \\
\text { 1b }\end{array}$ & $\begin{array}{c}\text { Seawater } \\
\text { small RO } \\
\text { Cyanex SX } \\
\text { 2a }\end{array}$ & $\begin{array}{c}\text { Seawater } \\
\text { small RO } \\
\text { Cyanex SX } \\
\text { 2b }\end{array}$ \\
\hline $\begin{array}{l}\text { Mill, feed chute, trommel screen materials and liners } \\
\text { Thickener materials } \\
\text { Thickener rake mechanism } \\
\text { Tank materials } \\
\text { Agitator materials } \\
\text { SX mixing tank/settler } \\
\text { SX agitator materials }\end{array}$ & $\begin{array}{l}\text { MS rubber liners } \\
\text { MSRL } \\
\text { SS316L } \\
\text { MSRL } \\
\text { SS316L } \\
\text { SS316L } \\
\text { SS316L }\end{array}$ & $\begin{array}{l}\text { MS rubber liners } \\
\text { MSRL } \\
2304 \\
2304 \\
\text { SS316L } \\
\text { SS316L } \\
\text { SS316L }\end{array}$ & $\begin{array}{l}\text { MS rubber liners } \\
\text { MSRL } \\
\text { SAF2507 } \\
\text { MSRL } \\
\text { SAF2507 } \\
\text { SAF2507 } \\
\text { SAF2507 }\end{array}$ & $\begin{array}{l}\text { MS rubber liners } \\
\text { MSRL } \\
\text { SAF2507 } \\
\text { SAF2507 } \\
\text { SAF2507 } \\
\text { SAF2507 } \\
\text { SAF2507 }\end{array}$ \\
\hline
\end{tabular}




\section{Uranium recovery from high chloride sulphate leach solutions}

\begin{tabular}{|c|c|c|c|c|}
\hline \multicolumn{5}{|c|}{$\begin{array}{l}\text { Table III } \\
\text { Key solvent extraction circuit differentials for treated water and seawater flow sheet options }\end{array}$} \\
\hline SX circuit differentials & Extract & Scrub & Strip & Regen \\
\hline $\begin{array}{l}\text { Option } 1 \text { - treated water with Alamine } 336 \mathrm{SX} \text { stages } \\
\text { Area of settler }\left(\mathrm{m}^{2}\right) \\
\text { Volume of mixing tanks }\left(\mathrm{m}^{3}\right)\end{array}$ & $\begin{array}{l}4 \\
153 \\
23\end{array}$ & $\begin{array}{l}3 \\
26 \\
13\end{array}$ & $\begin{array}{l}4 \\
26 \\
13\end{array}$ & $\begin{array}{l}1 \\
26 \\
13\end{array}$ \\
\hline $\begin{array}{l}\text { Option } 2 \text { - seawater with Cyanex } 272 \text { SX stages } \\
\text { Area of settler }\left(m^{2}\right) \\
\text { Volume of mixing tanks }\left(m^{3}\right)\end{array}$ & $\begin{array}{c}3 \\
153 \\
23\end{array}$ & $\begin{array}{c}2 \\
12 \\
7\end{array}$ & $\begin{array}{c}5 \\
12 \\
7\end{array}$ & $\begin{array}{c}0 \\
12 \\
7\end{array}$ \\
\hline $\begin{array}{l}\text { Is there a differential between the two circuits? Yes } \sqrt{ } \text {, No } x \\
\text { No. of equipment } \\
\text { Equipment size } \\
\text { Material of construction }\end{array}$ & $\begin{array}{l}\sqrt{ } \\
x \\
\sqrt{ }\end{array}$ & $\begin{array}{l}\sqrt{ } \\
\sqrt{ } \\
\sqrt{ }\end{array}$ & $\begin{array}{l}\sqrt{ } \\
\sqrt{ } \\
\sqrt{ }\end{array}$ & $\begin{array}{l}\sqrt{ } \\
\sqrt{ } \\
\sqrt{ }\end{array}$ \\
\hline
\end{tabular}

Table IV

Differential design parameters affecting operating costs for treated water and seawater flow sheets

\begin{tabular}{|c|c|c|}
\hline & Treated water with Alamine $336 \mathrm{SX}$ & Seawater with Cyanex 272 SX \\
\hline $\begin{array}{l}\text { Common design parameters } \\
\mathrm{PLS} \text { feed flow }\left(\mathrm{m}^{3} / \mathrm{h}\right) \\
\mathrm{U}_{3} \mathrm{O}_{8} \mathrm{PLS} \text { concentration (mg/L) }\end{array}$ & $\begin{array}{l}382 \\
834\end{array}$ & $\begin{array}{l}382 \\
834\end{array}$ \\
\hline $\begin{array}{l}\text { Differential design parameters } \\
\text { SWRO plant capacity (nominal) }(\mathrm{m} 3 / \mathrm{h}) \\
\text { Treated water chloride concentration }(\mathrm{mg} / \mathrm{L}) \\
\text { PLS chloride concentration }(\mathrm{g} / \mathrm{L}) \\
\mathrm{SX} \text { organic loading }\left(\mathrm{g} / \mathrm{L} \mathrm{U}_{3} \mathrm{O}_{8}\right) \\
\mathrm{SX} \text { extractant volume fraction }(\% \mathrm{v} / \mathrm{v}) \\
\mathrm{SX} \text { phase modifier volume fraction }(\% \mathrm{v} / \mathrm{v}) \\
\mathrm{SX} \text { diluent volume fraction }(\% \mathrm{v} / \mathrm{v}) \\
\mathrm{SX} \text { scrub liquor concentration }\left(\mathrm{g} / \mathrm{L} \mathrm{H}_{2} \mathrm{SO}_{4}\right) \\
\mathrm{SX} \text { strip liquor concentration }\left(\mathrm{g} / \mathrm{L} \mathrm{H}_{2} \mathrm{SO}_{4}\right) \\
\mathrm{SX} \text { regeneration } \mathrm{Na}_{2} \mathrm{CO}_{3}(\mathrm{~g} / \mathrm{L}) \\
\mathrm{SX} \text { regeneration } \mathrm{NaOH}(\mathrm{g} / \mathrm{L})\end{array}$ & $\begin{array}{c}200 \\
100 \\
0 \\
4.8 \\
4.5 \\
2.25 \\
93.3 \\
10 \\
435 \\
100 \\
50\end{array}$ & $\begin{array}{c}80 \\
100 \\
20 \\
10.7 \\
3.5 \\
- \\
96.5 \\
50 \\
411 \\
\text { No regen. } \\
\text { No regen. }\end{array}$ \\
\hline
\end{tabular}

throughout the rest of the uranium circuit was the same for both flow sheets.

The SX equipment for the scrubbing and stripping sections of the treated water option (Alamine 336 organic) was approximately double the size of that in the seawater option (Cyanex 272 organic). The sizes of the extraction circuits for the two flow sheets were the same. For the seawater-Cyanex 272 option, chlorides will be present in the extraction and scrubbing sections of the SX circuit, in the PLS, and the entrained aqueous within the loaded organic. The acidic raffinate containing chlorides is returned to CCD as wash liquor and eventually to leach to build up uranium tenor. The scrub liquor is recycled to the first SX stage. The scrubbed organic, free of chlorides, proceeds to stripping. Mass balance modelling showed that chloride transfer to the stripping circuit is negligible due to the flow rate of the scrub liquor and assumed PLS entrainment concentration. Furthermore, the already low concentrations of chlorides will be further diluted to trace amounts before entering nanofiltration. For simplicity, it was assumed that materials of construction are the same throughout each SX circuit.

\section{OPEX differentials}

The main differentials affecting OPEX can be attributed to the SX circuit size, number of unit operations, organic loadings, and reagent requirements for scrubbing, stripping and regeneration. OPEX is also affected by the desalination plant size. Design parameters affecting OPEX are summarized in Table IV.

\section{Techno-financial evaluation Overall basis of comparison}

Analysis was done on a bare-bones basis, in real terms, and excludes the effects of taxes, interest, financing terms, or any cost escalation. The costs shown are not to be regarded as definitive, but rather differential costs relative to the basecase option 1a. Any costs considered to be common between the various options were excluded from the analysis. The technical basis for comparison of the system economics is provided in Table $\mathrm{V}$.

\section{CAPEX costing and assumptions}

The CAPEX estimate was based on the following:

Differences in the major mechanical equipment

> The use of typical process design parameters (PDP) for compiling the mass balances that were then used to size major equipment

> Mechanical equipment costs were determined from recently executed studies, DRA's internal database, and selected vendor quotes (Heyns, 2017; Pryor, 2017) 


\section{Uranium recovery from high chloride sulphate leach solutions}

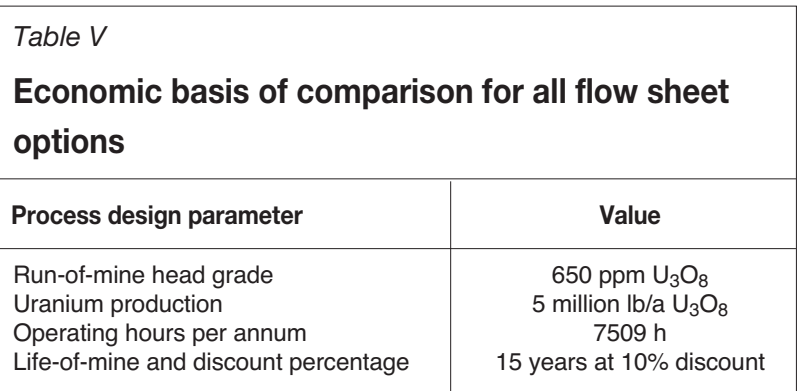

> Internal DRA factors were applied to the two SX circuit mechanical costs for civils, structural (supply and erection), platework (supply and erection), mechanical erection, piping (supply and installation), electrical, control and instrumentation (supply and installation), transport, project services, preliminary and general costs

> For the smaller SWRO plant, it was assumed that two SWRO skids, each capable of producing $55 \mathrm{~m}^{3} / \mathrm{h}$ (at average water temperature), would be required. In winter, at low water temperature, the two skids would produce $>100 \mathrm{~m}^{3} / \mathrm{h}$ and in summer would be able to produce more than the required amount $\left(80 \mathrm{~m}^{3} / \mathrm{h}\right.$, nominal)

> For the large SWRO plant, it was assumed that three SWRO skids, each capable of producing $83 \mathrm{~m}^{3} / \mathrm{h}$ (at average water temperature), would be required. In winter, at low water temperature, the three skids would produce $>220 \mathrm{~m}^{3} / \mathrm{h}$ and in summer would be able to produce more than the required amount $\left(200 \mathrm{~m}^{3} / \mathrm{h}\right.$, nominal)

> Piping was excluded as a differential as it was assumed to be high-density polyethylene (HDPE)

> Pump costing was excluded as a differential. It was assumed that slurry pumps in both flow sheets would have high-chrome metal impellers and liners and solution pumps would have ethylene propylene diene monomer (EPDM) rubber impellers and liners.

\section{OPEX costing and assumptions}

\section{Reagents}

Reagent costs were obtained from DRA's recently updated reagent database. Reagent consumptions were based on test work (ANSTO test work in the case of SX) and were determined using high-level mass balances. Reagent consumptions for the RO plants were based on estimates.

\section{Power}

Power consumption and labour costs for the RO plants were provided by Prentec (Pryor, 2017). The power estimate included seawater abstraction into the product water tank. The estimate assumed that desalination would be at the coast and excluded delivery to the mine. Power for the SX circuit was estimated from equipment sizing. Power for the rest of the uranium processing plant is not a differential and was therefore not included.

\section{Maintenance}

Maintenance costs are factored for mechanical replacement cost, platework and rubber lining maintenance, and valve maintenance. Piping maintenance was excluded.

\section{Consumables}

Grinding media for milling for option 1 is forged steel balls and for option 2 the media is of the high-chrome variety. Grinding media consumption was assumed the same, with costs of materials of construction varying. Membrane life for the SWRO plants was five years. Mill liners were excluded as a consumable cost.

\section{Financial analysis}

The CAPEX and OPEX cost estimates are summarized in the bar charts shown in Figures $5 a$ and $5 b$. The bars show the estimated costs for a $75 \%$ confidence range, as well as the maximum and minimum ranges expected. OPEX estimates are annual expected costs.

The OPEX estimates in Figure $5 \mathrm{a}$ were based on upside and downside supply cost. The main factors affecting OPEX included:

> SX strip liquor acid consumption: the two flow sheets use different amounts of acid for stripping uranium. Option 1 requires more acid. Acid supply costs are based on US $\$ 109$ per ton, with an upside of US $\$ 60$ per ton and downside of US\$140 per ton (based on feedback from numerous reputable reagent suppliers).

- SX diluents contribute a noteworthy portion to the OPEX cost in both options.
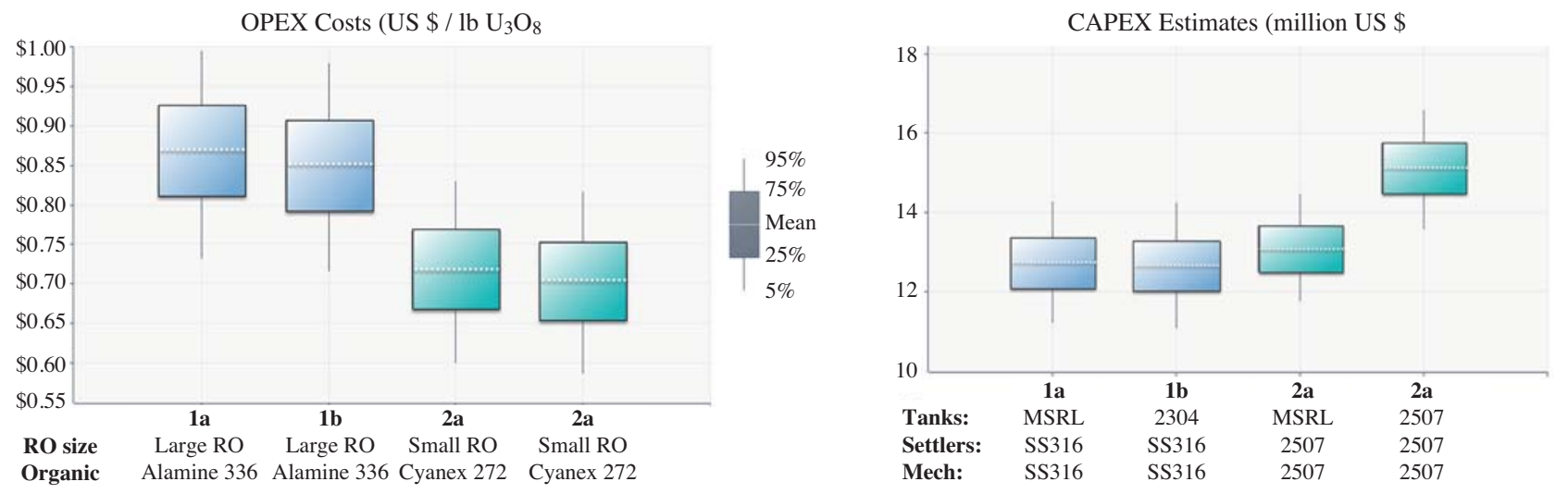

Figure 5-(a) OPEX cost estimates ( $\$$ per pound $\mathrm{U}_{3} \mathrm{O}_{8}$ ) and (b) CAPEX cost estimates (\$ million) 


\section{Uranium recovery from high chloride sulphate leach solutions}

- SX regeneration agents, sodium carbonate $\left(\mathrm{Na}_{2} \mathrm{CO}_{3}\right)$ and sodium hydroxide $(\mathrm{NaOH})$, contribute to a higher baseline OPEX for option 1. Option 2 has no organic regeneration step in SX. The $\mathrm{Na}_{2} \mathrm{CO}_{3}$ cost is based on US $\$ 594$ per ton, with a range from US $\$ 416$ to US $\$ 772$ per ton.

> Power usage for a large RO plant increases the OPEX in option 1.

The box-plot graph shown in Figure 6 shows the differential net present cost (NPC) for each option relative to the base case.

Figure 6 demonstrates that all options relative to the base case will return improved cash flows over a 15 year life-ofmine, despite the higher capital expenditure required. The flow sheet options that consider the use of seawater, namely options $2 \mathrm{a}$ and $2 \mathrm{~b}$, provide the highest cost savings over a 15 -year life-of-mine. The expected life-of-mine economic benefit is calculated to be between US\$0.5 million and US $\$ 4.5$ million. Option $1 \mathrm{~b}$ is expected to provide some cost benefit when compared with the base-case option 1a, mainly because of reduced platework maintenance costs. There is, however, a moderate likelihood of breaking even with the base-case option, in terms of life-of-mine cost savings.

\section{Sensitivity analysis}

Tornado charts, indicating the major uncertainty contributors, for options $1 \mathrm{~b}, 2 \mathrm{a}$, and $2 \mathrm{~b}$ relative to the base-case option $1 \mathrm{a}$ are shown in Figure 7, Figure 8, and Figure 9, respectively.

In Figure 7, the greatest uncertainty lies in the platework maintenance cost for the option $1 \mathrm{~b}$ differential NPC. In option $1 \mathrm{a}$, it is the cost of maintaining MSRL platework compared with maintaining SS316/2304 platework in option 1b.
For option 2a in Figure 8, the greatest uncertainty lies in the super-duplex stainless steel mechanical cost (rake mechanism). The power cost of the RO plants, SX diluents, and acid supply costs are significant contributors to economic uncertainty. Nonetheless, even at the extremities of these supply costs, this option using seawater is expected to return economic benefits to the project.

For option $2 \mathrm{~b}$ in Figure 9, the greatest uncertainty lies in the super-duplex stainless steel mechanical and platework costs. At the downside of the SAF2507 supply cost estimate, the use of high-alloy materials, for a high-chloride circuit is not expected to return economic benefits.

\section{Conclusions and recommendations}

The aim of this trade-off study was to propose a hypersalinetolerant uranium processing flow sheet through the use of an alternative uranium SX organic, Cyanex 272, and to determine whether this is an economically viable option.

A stochastic approach was used to quantify the differentials in expenditure between uranium processing with SWRO-treated water and seawater. Together with a basic high-level evaluation of the CAPEX and OPEX requirements, a comparison of the economics revealed that a flow sheet incorporating a hypersaline water source is an economical option when MSRL platework and super-duplex SAF2507 mechanicals are used. Nevertheless, the concentration of $\mathrm{U}_{3} \mathrm{O}_{8}$ in the PLS plays key part in the selection of the process route and the SX purification route.

Chlorides in combination with sulphate salts and acidic solutions are not well understood in industry. Engineering design companies should open a dialogue with steel suppliers and vendors to find suitable MoC for these corrosive

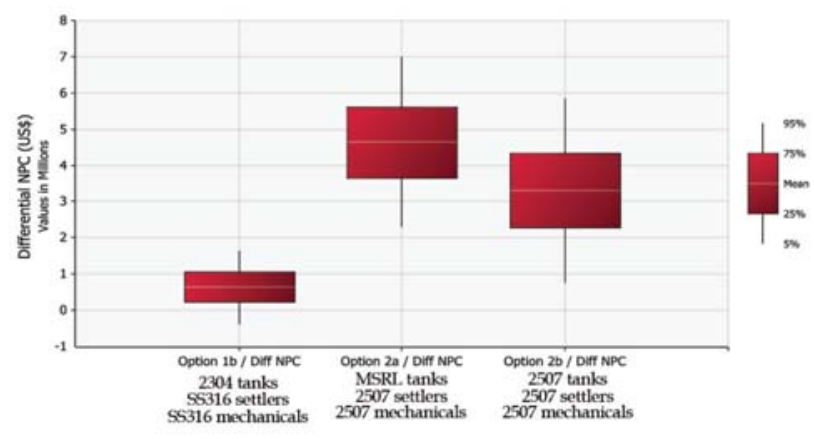

Figure 6-Differential net present cost (NPC) of the various options relative to option 1 (15-year LoM, 10\% discount)

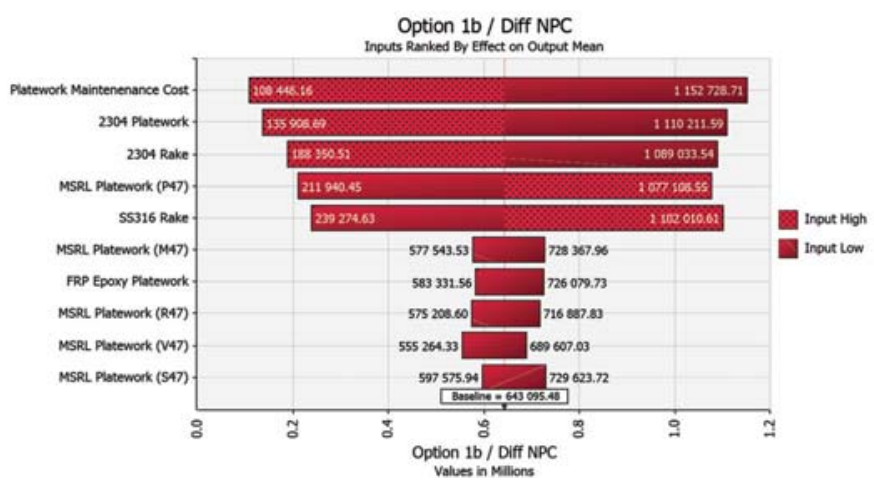

Figure 7-Tornado plot of differential NPC of options relative to option 1b (15-year LoM, 10\% discount) 


\section{Uranium recovery from high chloride sulphate leach solutions}

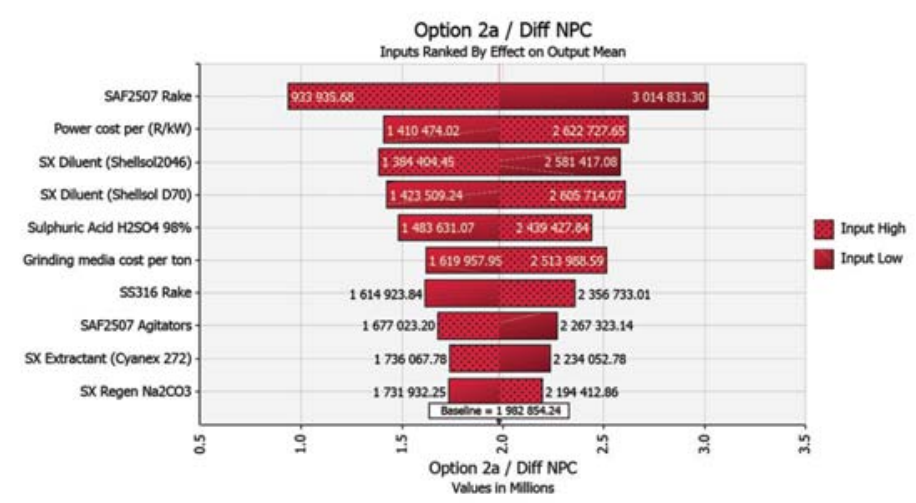

Figure 8-Tornado plot of differential NPC of option 2a relative to option 1 (15-year LoM, 10\% discount)

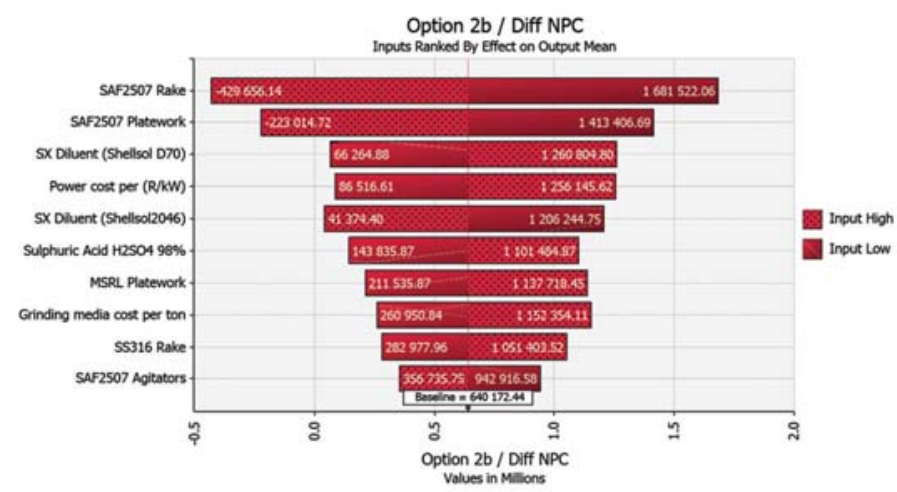

Figure 9-Tornado plot of differential NPC of option $2 \mathrm{~b}$ relative to option 1 (15-year LoM, $10 \%$ discount)

applications, which are becoming more commonplace as orebody grades decline and clean water sources become scarce.

\section{Acknowledgements}

Our thanks to ANSTO for their valued input, professional research, and comments on the process design parameters for the chloride-tolerant uranium SX technology. Prentec and Mixtec are thanked for providing comprehensive costing.

\section{References}

Ballestrin, S., Low, R., Reynaud, G., and Crane, P. 2014. Honeymoon mine Australia: Commissioning and operation of the process plant using a novel solvent extraction reagent mixture in a high chloride environment. Proceedings of ALTA 2014 Uranium-REE. ALTA Metallurgical Services, Australia. pp. 291-308.

Brown, A.J. and Haydon, B.C. 1979. Comparison of liquid and resin ionexchange processes for the purification and concentration of uraniferous solutions. CIM Bulletin, vol. 72, no. 805. pp. 141-149.

DuDLEy, K.A. and SuMNER, R.J. 2014. Solvent extraction process. International patent WO2014040136. BHP Billiton Olympic Dam Corporation Pty Ltd.

Goldswain, B. and Rogers, T. 2017a. Stainless steel for engineers. Consulting Engineers South Africa, CESA-614-11/2017. pp. 1-32.

Goldswain, B. and Rogers, T. 2017b. Costs and materials of construction for corrosive applications. Interviewed by Eleanore Forner. [meeting] DRA Global, Sunninghill, South Africa, 23 May 2017.

Heyns, T. 2017. Budget quote on agitator motors, blades and shafts in selected materials of construction. Mixtec, Germiston, South Africa.
Morais, C.A. and LADEIRA, A.C. 2008. The influence of competitive species on uranium recovery using resin and solvent extraction techniques. Proceedings of the Sixth International Symposium of Hydrometallurgy. Young, C.A., Taylor, P.R., and Anderson C.G. (eds.). Society for Mining, Metallurgy \& Exploration, Inc., Littleton, CO. pp. 292 - 296.

OUTокUмPu. 2013. Duplex stainless steels. https://www.outokumpu.com/ SiteCollectionDocuments/Duplex_Stainless_Brochure.pdf [accessed 22 January 2017].

ОuтокимР. 2015. Storage tank shell thickness calculation. http://steelfinder.outokumpu.com/storage-tank/ [accessed 16 May 2017].

Pryor, M. 2017. Budget estimates of two seawater reverse osmosis plants. Process Manager, Prentec, Kempton Park, South Africa.

QuinN, J.E., Wilkins, D., and SoldENHOFF, K.H. 2013. Solvent extraction of uranium from saline leach liquors using DEHPA/Alamine 336 mixed reagent. Hydrometallurgy, vol. 134-135, no. 0. pp. 74-79.

QuinN, J.E. and SoLDENHOFF, K.H. 2015. Process for uranium recovery using Cyanex 271. Hydrometallurgy, vol. 152. pp. 7-12.

Soldenhoff, K., Wilkins, D., ShamieH, M., and Ring, R. 2000. Solvent extraction of uranium in the presence of chloride. Proceedings of the International Symposium on the Process Metallurgy of Uranium: 30th Annual Hydrometallurgical Meeting. Ozberk, E. and Oliver, A.J. (eds). Canadian Institute of Mining, Metallurgy and Petroleum, Montreal, Canada. pp. 339-351.

Soldenhoff, K., Wilkins, D., Shamieh, M., and Manis, A. 2005. Mini-plant testing of uranium solvent extraction process for acid leach liquors containing chloride. Proceedings of the 17th International Solvent Extraction Conference, Beijing, China. Hara, T. (ed.). Taylor \& Francis/Balkema, The Netherlands.

VAN Tonder, D. and Kotze, M. 2007. Uranium recovery from acid leach liquors: IX or SX? Proceedings of the Alta 2007 Uranium Conference. ALTA Metallurgical Services, Melbourne, Australia. p. 226. 